\title{
Expression of RNAs Coding for Metal Transporters in Blood of Patients with Huntington's Disease
}

\author{
Monika Szeliga ${ }^{1}$ - Aleksandra Różycka² Paulina Jędrak $^{3} \cdot$ Sylwia Barańska ${ }^{3}$. \\ Piotr Janik $^{4,5} \cdot$ Zygmunt Jamrozik $^{5} \cdot$ Jan Albrecht $^{1}$
}

Received: 26 August 2015/Revised: 7 October 2015/Accepted: 8 October 2015/Published online: 15 October 2015

(C) The Author(s) 2015. This article is published with open access at Springerlink.com

\begin{abstract}
Recent studies have demonstrated elevated levels of iron (Fe) in brains of patients with Huntington's disease (HD). Striatal cells carrying mutated Huntingtin presented increased sensitivity to cadmium (Cd) toxicity, decreased sensitivity to manganese (Mn) toxicity and deficits in Mn uptake. The hypothesis arose that the observed alterations result from the altered expression and/or activity of proteins engaged in the transport of these metals, that is: transferrin (TF), transferrin receptor (TFR), divalent metal transporter 1 (DMT1) and ZIP8 protein. Here we examined the expression levels of genes encoding these proteins in blood of HD patients and control subjects. A decreasing tendency in the level of $T F$ transcript and increasing tendency of SLC11A2 mRNA encoding DMT1 was observed in the blood of HD patients compared to the control subjects, but neither attained statistical significance. No changes were found in the levels of TFRC coding for TFR and SLC39A8 coding for ZIP8 between HD patients and
\end{abstract}

Special Issue: 40th Year of Neurochemical Research.

Monika Szeliga

mszeliga@imdik.pan.pl

1 Department of Neurotoxicology, Mossakowski Medical Research Centre Polish Academy of Sciences, 5 Pawińskiego Str., 02-106 Warsaw, Poland

2 Faculty of Horticulture, Biotechnology and Landscape Architecture, Warsaw University of Life Sciences, 166 Nowoursynowska Str., 02-787 Warsaw, Poland

3 Department of Molecular Biology, University of Gdańsk, 59 Wita Stwosza Str., 80-308 Gdańsk, Poland

4 Department of Neurology, The Wolski Hospital im Dr Anny Gostyńskiej, 17 Kasprzaka Str., 01-211 Warsaw, Poland

5 Department of Neurology, Medical University of Warsaw, 1 Banacha Str., 02-097 Warsaw, Poland controls. The results indicate that HD-associated changes in metal homeostasis occur are not related to mechanisms other than the expression level of the here analyzed metal transporters.

Keywords Huntington's disease - Metal transporter - TF . TFR · DMT1 · ZIP8

\section{Introduction}

Huntington's disease (HD) is a chronic and progressive neurodegenerative disease clinically characterized by chorea, psychiatric, psychological and intellectual disorders, and neuropathologically by the loss of striatal projection neurons [1]. Currently, there is no effective treatment to delay the onset or significantly slow the progression of HD. HD is an autosomal-dominant disorder caused by mutation of the IT15 gene (also known as HTT) encoding huntingtin (Htt). The detailed role of wild-type $\mathrm{Htt}$ is unclear, although a growing body of studies indicates its function in brain development and embryogenesis [2], autophagy [3], and regulation of gene transcription [4, 5]. It also protects against cell death and has anti-apoptotic properties [6, 7]. Huntingtin knockout mice exhibit embryonic lethality [8]. Wild-type human Htt contains the polyQ domain composed of 11-34 glutamine (CAG) residues. HD is caused by an abnormal (>35) expansion of the $\mathrm{CAG}$ repeats [1]. Proteolysis of mutant $\mathrm{Htt}(\mathrm{mHtt})$ releases multiple N-terminal Htt fragments containing expanded polyQ repeats which aggregate in nucleus and cytoplasm of affected neurons [9]. It is still unclear whether the aggregates are cytotoxic per se, although the cytotoxic effect of $\mathrm{mHtt}$ have been documented in distinct HD models [10]. 
Recent findings identified several proteins interacting with mHtt which may contribute to the pathology of HD [9].

Lack of correlation between the selective degeneration and widespread expression of mHtt strongly suggests that other factors may increase the vulnerability of striatal neurons to the pathophysiological mechanisms underlying HD [11, 12]. Growing evidence links HD to altered metal homeostasis. Increased levels of iron $(\mathrm{Fe})$ and copper $(\mathrm{Cu})$ were found in postmortem brain tissue from patients with HD compared with control subjects [13-15]. Studies on a mutant STH $d h^{Q 111 / Q 111}$ cell line, a striatal neuronal cell line model of HD, revealed changes in Fe signaling and elevated level of transferrin receptor (TfR) in comparison with the wild-type $\mathrm{STH} d h^{Q 7 / Q 7}$ cells [16]. The mutant STH $d h^{Q 111 / Q 111}$ cells displayed an increased sensitivity to cadmium $(\mathrm{Cd})$ toxicity and resistance to manganese $(\mathrm{Mn})$ toxicity [17]. Of note, this neuroprotective interaction was highly metal specific. Moreover, a decreased accumulation of Mn was observed in the mutant STH $d h^{Q 111 / Q 111}$ cells and in the YAC128Q HD mouse model [17]. The hypothesis arose that the observed alterations result from the altered expression of proteins engaged in the transport of heavy metals, that is: divalent metal transporter 1 (DMT1), ZIP8 protein, transferrin (TF) and transferrin receptor, TfR [19]. As a step towards verifying the hypothesis, we compared the expression levels of genes encoding these proteins in blood of HD patients and control subjects.

\section{Materials and Methods}

\section{Participants}

Fifteen HD patients were recruited from the Department of Neurology, Medical University of Warsaw, Warsaw, Poland (seven patients) and the Specialist Hospital św. Wojciecha in Gdańsk, Poland (eight patients). All patients were positive on the molecular test for the presence of a CAG triplet $>35$ repeats in the HTT gene. They also manifested clinical signs and symptoms of HD. Clinical examination was performed by trained [formal and certified training within the European Huntington's Disease Network (EHDN)] neurologists and psychologists and included: motor and behavioural rating due to Unified Huntington's Disease Rating Scale (UHDRS) and neuropsychological rating for depression (Hamilton and Beck's questionnaires), TFC (Total Functioning Capacity) and cognitive assessment (Stroop Test, Verbal Fluency Test, Symbol Digit Modality Test). A control group (age and gender matched) included volunteers with no neurodegenerative disorders. All of the participants received verbal and written information about the study, and signed an informed consent form. The local Ethics Committees approved all procedures. Table 1 shows the subjects' gender, age and the length of the CAG repeat on the expanded allele.

\section{RNA Extraction}

Peripheral blood lymphocytes were isolated from blood of patients and control subjects from the Medical University of Warsaw, Poland. First, the blood sample was diluted with an equal volume of phosphate buffered saline (PBS) and poured onto the Ficoll solution (Sigma-Aldrich). The test tube was centrifuged for $20 \mathrm{~min}$ at $1600 \mathrm{rpm}$. The ring with white blood cells was harvested and washed twist with PBS. Next, total RNA was extracted from the lymphocytes using TRI Reagent BD (Sigma-Aldrich), according to the manufacturer's protocol. Total RNA was extracted from whole blood of patients and control subjects from the Specialist Hospital św. Wojciecha in Gdańsk, Poland, using PAXgene Blood RNA Kit (Qiagen) according to the manufacturer's protocol. Total RNA concentration was measured with a NanoDrop 1000 Spectrophotometer.

\section{Reverse Transcription and Real-Time PCR}

One microgram of RNA was digested with DNaseI (Invitrogen) and reverse-transcribed using a High-Capacity cDNA Reverse Transcription Kit (Applied Biosystems) according to the manufacturer's protocol. Two independent reverse transcription reactions were performed for every RNA sample. Real-time PCR was performed using TaqMan Gene Expression Assays listed in Table 2 and TaqMan Universal PCR Master Mix (Applied Biosystems) according to the manufacturer's protocol. The reactions were incubated at $95{ }^{\circ} \mathrm{C}$ for $10 \mathrm{~min}$, followed by 45 cycles of $95{ }^{\circ} \mathrm{C}$ for $15 \mathrm{~s}$ and $60{ }^{\circ} \mathrm{C}$ for $1 \mathrm{~min}$ using an Applied Biosystems 7500 Sequence Detection System. Relative expression was normalized to the expression of $A C T B$ gene encoding $\beta$-actin and calculated using the $\Delta \Delta \mathrm{C}_{\mathrm{T}}$ method [20].

\section{Statistical Analyses}

The data were analyzed using the paired Student's $t$ test. In the box plots, the boundary of the box closest to zero

Table 1 Clinical and genetic characteristics of HD patients and healthy controls

\begin{tabular}{lllll}
\hline Samples & No. & Sex (women/men) & Age (years) & CAG size \\
\hline Control & 15 & $9 / 6$ & $46(27-70)$ & - \\
HD & 15 & $9 / 6$ & $57(33-78)$ & $41(39-51)$ \\
\hline
\end{tabular}

Age and CAG size are expressed as median values (min-max). The number of $\mathrm{CAG}$ repeats is missing for $4 \mathrm{HD}$ patients 
Table 2 TaqMan gene expression assays used for realtime PCR

\begin{tabular}{llll}
\hline Transcript & Assay ID & GeneBank sequence & Exon boundary \\
\hline TF & Hs01067777_m1 & AK222755.1 & $14-15$ \\
TFRC & Hs00951083_m1 & AB209254.1 & $16-17$ \\
SLC11A2 & Hs00167206_m1 & AB004857.1 & $15-16$ \\
SLC39A8 & Hs00223357_m1 & AB040120.1 & $3-4$ \\
ACTB & 4326315E & NM_001101.2 & 1 \\
\hline
\end{tabular}

indicates the $25^{\text {th }}$ percentile, the line in the middle is plotted at the median, and the boundary of the box farthest from zero indicates the $75^{\text {th }}$ percentile. The Pearson's correlation coefficient was used to identify correlations between the number of CAG repeats and the level of SLC11A2 and TF mRNA levels normalized to ACTB mRNA.

\section{Results}

We performed real-time PCR analysis of expression of $T F$, TFRC, SLC11A2 (coding for DMT1) and SLC39A8 (coding for ZIP8) genes in blood of HD and control subjects. A statistically insignificant decreasing tendency in $T F$ mRNA level was observed in HD patients (mean value: 0.8369; median value: 0.8285 ) compared to controls (mean value: 1.072; median value: 1.034) (Fig. 1a). Of note, $T F$ mRNA was undetectable in 3 out of $15 \mathrm{HD}$ patients, therefore the analysis of $T F$ expression was performed on $12 \mathrm{HD}$ and 12 healthy subjects. No difference was found in TFRC mRNA level between controls (mean value: 1.080; median value: 1.109) and HD patients (mean value: 1.124; median value: 1.197) (Fig. 1b). SLC11A2 mRNA showed a tendency to increase in HD patients (mean value: 1.748; median value: 1.428 ) with respect to controls (mean value: 1.259; median value: 0.9238), although this difference was not statistically significant $(p>0.05$; Fig. 1c). There was no statistically significant difference between the level of SLC39A8 transcript in controls (mean value: 1.174; median value: 1.129 ) and HD patients (mean value: 1.133 ; median value: 0.8990) (Fig. 1d).

Next we examined whether the alterations in $T F$ and SLC11A2 mRNA levels observed in blood of HD patients were associated with the number of CAG repeats. As data concerning CAG size were missing for 4 samples, this analysis was performed on 8 and 11 samples in the case of $T F$ and SLC11A2 mRNA, respectively. We found no correlation between the number of CAG repeats and the level of TF (r $=0.1361, \quad P=0.7480$, Pearson's test $)$ or
Fig. 1 Relative levels of manganese transporters transcripts in blood from control and HD subjects. Levels of $T F$ (a), TFRC (b), SLC11A2 (c) and SLC39A8 (d) mRNA were normalized to beta-actin (ACTB). HD, HD patients. The boundary of the box closest to zero indicates the $25^{\text {th }}$ percentile, the line in the middle is plotted at the median, and the boundary of the box farthest from zero indicates the $75^{\text {th }}$ percentile
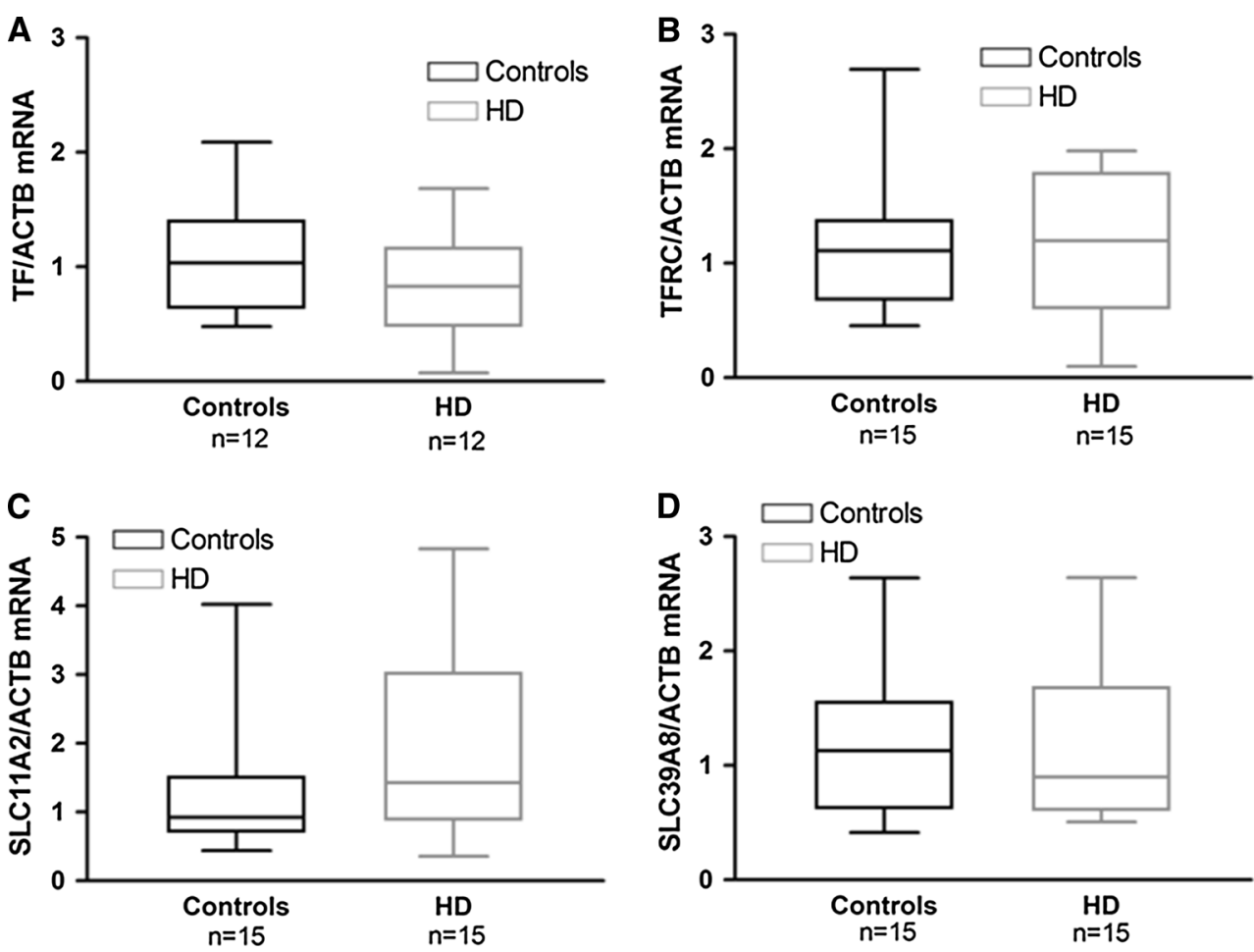
SLC11A2 (r = -0.4429, $P=0.1725)$ mRNA (Fig. 2a, b, respectively).

\section{Discussion}

Fe and Mn play roles in a number of physiological processes, yet the exposure to excessive levels of these metals can cause a damage to the nervous system. Association between altered homeostasis of these metal and neurodegenerative disorders, including HD, has been frequently postulated (for extensive reviews, please refer to [21-24]). Alterations in Fe signaling were observed in a mutant $\mathrm{STH} d h^{Q 111 / Q 111}$ cell line, a striatal neuronal cell line model of HD as compared to the wild-type STH $d h^{Q 7 / Q 7}$ cells [16]. Increased level of Fe was found in R6/2 HD mice [25] and in brain tissue from HD patients [13-15]. Recent studies revealed increased sensitivity of STH $d h^{Q 111 / Q 111}$ cell line to $\mathrm{Cd}$ toxicity and resistance to Mn toxicity. Moreover, the same studies showed a decreased Mn accumulation in STH $d h^{Q 111 / Q 111}$ cells and YAC128Q HD mice following in vivo Mn exposure [17, 18].

Here we addressed the hypothesis that disturbed $\mathrm{Fe}$ and Mn homeostasis observed in HD models are caused by changes in the function of metal-transporting proteins and we asked the question whether this pathogenetic pattern also holds for human HD. As a step toward this end, we analysed the expression of genes encoding the four proteins most evidently involved in the transport of these metals and tightly link $\mathrm{Fe}$ and $\mathrm{Mn}$ homeostasis to each other. A growing body of evidence suggests that transferrin (TF), the main Fe-carrying protein in neurons [26] and transferring receptor (TFR) play crucial role in brain Mn transport [19, 27, 28]. STH $d h^{Q 111 / Q 111}$ cells exhibit alterations in the level of TFR protein: its decreased level was found in the early passages of this cell line [16], while the late passages presented an increased level of this protein [18] compared with a wild-type cells STH $d h^{Q 7 / Q 7}$. While our data demonstrate a decreasing tendency in the level of $T F$ transcript in the blood of HD patients compared to the control subjects, no correlation was observed between the relative level of $T F$ transcript and the numbers of CAG repeats, a hallmark of $\mathrm{HD}$. We have also observed lack of differences in the level of TFRC transcript between HD patients and controls.

Another protein involved in $\mathrm{Fe}$ and $\mathrm{Mn}$ delivery is DMT1 (divalent metal transporter-1, also known as NRAMP-2) [29-31]. This protein is of interest as it has been implicated in the transfer of $\mathrm{Mn}$ and other metals across the blood-brain barrier [32]. Dysfunction of DMT1 has been linked to many disorders including Parkinson's [33] and Alzheimer's [34] disease. A slight trend toward increased DMT1 level was observed in STH $d h^{Q 111 / Q 111}$ cells compared with the wild-type cells [18]. In our study, SLC11A2 mRNA encoding DMT1 showed a tendency to increase in HD patients compared with controls. However, as was the case with the $T F$ transcript, the increase did not reach statistical significance and the slight changes did not correlate with the number of $\mathrm{CAG}$ repeats. It will have to be verified whether the tendencies towards decrease/increase noted above on the limited number of samples will reach statistical significance when larger amounts of material become available.

We have also examined the expression of SLC39A8 encoding ZIP8, as this protein is involved in Fe transport in hippocampal neurons [35] and some findings suggest its role in Mn transport [36, 37]. A point mutation p.A391T in SLC39A8 has been associated with some disorders including schizophrenia [38]. We have found no differences in the level of SLC39A8 transcript between the blood of HD and control subjects.

In conclusion, our study failed to demonstrate changes in the expression level of genes coding for the major brain transporters of Fe and Mn: TF, TFR, DMT1 and ZIP8 between blood of HD patients and controls. If impaired metal homeostasis in human HD is related to the dysfunction of the group of metal transporters here analyzed, the underlying mechanisms will have to involve one or several steps post transcription. On the other hand, evidence has recently begun to accumulate suggesting a role
Fig. 2 Lack of correlation between the numbers of CAG repeats and the relative level of $T F$ (a) or SLC11A2 (b) mRNA in blood of HD patients. As data concerning the number of CAG repeats were missing for $4 \mathrm{HD}$ patients, the analysis was performed on 8 samples in case of $T F$ mRNA (a) and 11 samples in case of SLC11A2 mRNA (b)
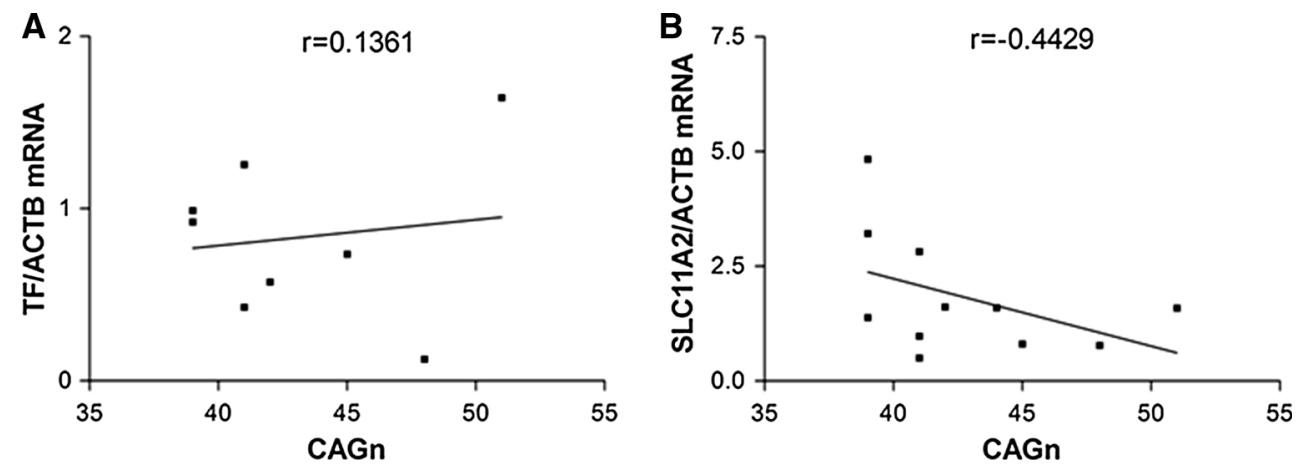
of efflux and efflux-mediating proteins in maintaining metal homeostasis (for an exhaustive review see Ref. [32]). The absence of changes in the expression of metal transporters dealt with in the present study does not exclude contribution of other transporting moieties that have attracted attention more recently, such as ZIP14, DAT, citrate transporters, Ca channels, SLC30A10 and ferroportin (for an exhaustive review see Ref. [32]). Most significantly, hypermanganesemia with associated Parkinson Disease symptoms has been found related to mutations in the SLC30A10, a member of the SLC30 solute carrier subfamily previously thought to serve as a specific $\mathrm{Zn}$ transporter [39, 40]. In this context, analysis of the expression and sequence of RNAs coding metal effluxmediating proteins in HD patients appears to be an interesting venue of further investigations.

It may be argued that the results of gene expression obtained from blood analysis may not be unconditionally representative for the expression patterns of metal transporters in the brain, a question that we were unable to attend practically. However, numerous recent reports have convincingly documented a good correlation between the brain tissue and peripheral readouts of other genes purportedly associated with the development of HD. Positive correlation in this regard has been noted, for instance, for TGF- $\beta 1$ [41] and Rho kinase pathway genes [42]. Clearly, the present results will have to be verified once access to representative brain tissue is gained.

Irrespective of the above considerations, it appears mandatory to use a functional approach, starting with comparing metal transport in lymphocytes derived from control and HD subjects.

Acknowledgments This study was supported by National Science Centre, Grant No. 2011/03/B/NZ2/01422.

Open Access This article is distributed under the terms of the Creative Commons Attribution 4.0 International License (http://crea tivecommons.org/licenses/by/4.0/), which permits unrestricted use, distribution, and reproduction in any medium, provided you give appropriate credit to the original author(s) and the source, provide a link to the Creative Commons license, and indicate if changes were made.

\section{References}

1. Kumar A, Kumar Singh S, Kumar V, Kumar D, Agarwal S, Rana MK (2015) Huntington's disease: an update of therapeutic strategies. Gene 556:91-97. doi:10.1016/j.gene.2014.11.022

2. Reiner A, Dragatsis I, Zeitlin S, Goldowitz D (2003) Wild-type huntingtin plays a role in brain development and neuronal survival. Mol Neurobiol 28:259-276

3. Kegel KB, Kim M, Sapp E, McIntyre C, Castaño JG, Aronin N, DiFiglia M (2000) Huntingtin expression stimulates endosomallysosomal activity, endosome tubulation, and autophagy. J Neurosci 20:7268-7278
4. Zuccato C, Cattaneo E (2007) Role of brain-derived neurotrophic factor in Huntington's disease. Prog Neurobiol 81:294-330

5. Benn CL, Sun T, Sadri-Vakili G, McFarland KN, DiRocco DP, Yohrling GJ, Clark TW, Bouzou B, Cha JH (2008) Huntingtin modulates transcription, occupies gene promoters in vivo, and binds directly to DNA in a polyglutamine-dependent manner. J Neurosci 28:10720-10733. doi:10.1523/JNEUROSCI.2126-08. 2008

6. Rigamonti D, Sipione S, Goffredo D, Zuccato C, Fossale E, Cattaneo E (2001) Huntingtin's neuroprotective activity occurs via inhibition of procaspase-9 processing. J Biol Chem 276: $14545-14548$

7. Leavitt BR, Raamsdonk JM, Shehadeh J, Fernandes H, Murphy Z, Graham RK, Wellington CL, Raymond LA, Hayden MR (2006) Wild-type huntingtin protects neurons from excitotoxicity. J Neurochem 96:1121-1129

8. Zeitlin S, Liu JP, Chapman DL, Papaioannou VE, Efstratiadis A (1995) Increased apoptosis and early embryonic lethality in mice nullizygous for the Huntington's disease gene homologue. Nat Genet 11:155-163

9. Li SH, Li XJ (2004) Huntingtin-protein interactions and the pathogenesis of Huntington's disease. Trends Genet 20:146-154

10. Cisbani G, Cicchetti F (2012) An in vitro perspective on the molecular mechanisms underlying mutant huntingtin protein toxicity. Cell Death Dis 3:e382. doi:10.1038/cddis.2012.121

11. Landwehrmeyer GB, McNeil SM, Dure LS 4th, Ge P, Aizawa H, Huang Q, Ambrose CM, Duyao MP, Bird ED, Bonilla E et al (1995) Huntington's disease gene: regional and cellular expression in brain of normal and affected individuals. Ann Neurol 37:218-230

12. Van Raamsdonk JM, Murphy Z, Slow EJ, Leavitt BR, Hayden MR (2005) Selective degeneration and nuclear localization of mutant huntingtin in the YAC128 mouse model of Huntington disease. Hum Mol Genet 14:3823-3835

13. Dexter DT, Carayon A, Javoy-Agid F, Agid Y, Wells FR, Daniel SE, Lees AJ, Jenner P, Marsden CD (1991) Alterations in the levels of iron, ferritin and other trace metals in Parkinson's disease and other neurodegenerative diseases affecting the basal ganglia. Brain 114:1953-1975

14. Bartzokis G, Cummings J, Perlman S, Hance DB, Mintz J (1999) Increased basal ganglia iron levels in Huntington disease. Arch Neurol 56:569-574

15. Bartzokis G, Lu PH, Tishler TA, Fong SM, Oluwadara B, Finn JP, Huang D, Bordelon Y, Mintz J, Perlman S (2007) Myelin breakdown and iron changes in Huntington's disease: pathogenesis and treatment implications. Neurochem Res 32:1655-1664

16. Trettel F, Rigamonti D, Hilditch-Maguire P, Wheeler VC, Sharp AH, Persichetti F, Cattaneo E, MacDonald ME (2000) Dominant phenotypes produced by the HD mutation in STHdh(Q111) striatal cells. Hum Mol Genet 9:2799-2809

17. Williams BB, Li D, Wegrzynowicz M, Vadodaria BK, Anderson JG, Kwakye GF, Aschner M, Erikson KM, Bowman AB (2010) Disease-toxicant screen reveals a neuroprotective interaction between Huntington's disease and manganese exposure. J Neurochem 112:227-237

18. Williams BB, Kwakye GF, Wegrzynowicz M, Li D, Aschner M, Erikson KM, Bowman AB (2010) Altered manganese homeostasis and manganese toxicity in a Huntington's disease striatal cell model are not explained by defects in the iron transport system. Toxicol Sci 117:169-179. doi:10.1093/toxsci/kfq174

19. Aschner M, Guilarte TR, Schneider JS, Zheng W (2007) Manganese: recent advances in understanding its transport and neurotoxicity. Toxicol Appl Pharmacol 221:131-147

20. Livak KJ, Schmittgen TD (2001) Analysis of relative gene expression data using real-time quantitative PCR and the 2(-Delta Delta C(T)) Method. Methods 25:402-408 
21. Whitnall M, Richardson DR (2006) Iron: a new target for pharmacological intervention in neurodegenerative diseases. Semin Pediatr Neurol 13:186-197

22. Avila DS, Puntel RL, Aschner M (2013) Manganese in health and disease. Met Ions Life Sci 13:199-227. doi:10.1007/978-94-0077500-8_7

23. Ward RJ, Zucca FA, Duyn JH, Crichton RR, Zecca L (2014) The role of iron in brain ageing and neurodegenerative disorders. Lancet Neurol 13:1045-1060. doi:10.1016/S1474-4422(14)70 $117-6$

24. Kwakye GF, Paoliello MM, Mukhopadhyay S, Bowman AB, Aschner M (2015) Manganese-induced Parkinsonism and Parkinson's disease: shared and distinguishable features. Int $\mathbf{J}$ Environ Res Public Health 12:7519-7540. doi:10.3390/ ijerph120707519

25. Chen J, Marks E, Lai B, Zhang Z, Duce JA, Lam LQ, Volitakis I, Bush AI, Hersch S, Fox JH (2013) Iron accumulates in Huntington's disease neurons: protection by deferoxamine. PLoS ONE 8(10):e77023. doi:10.1371/journal.pone.0077023

26. Leitner DF, Connor JR (2012) Functional roles of transferrin in the brain. Biochim Biophys Acta 1820:393-402. doi:10.1016/j. bbagen.2011.10.016

27. Malecki EA, Devenyi AG, Beard JL, Connor JR (1999) Existing and emerging mechanisms for transport of iron and manganese to the brain. J Neurosci Res 56:113-122

28. Gunter TE, Gerstner B, Gunter KK, Malecki J, Gelein R, Valentine WM, Aschner M, Yule DI (2013) Manganese transport via the transferrin mechanism. Neurotoxicology 34:118-127. doi:10.1016/j.neuro.2012.10.018

29. Garrick MD, Dolan KG, Horbinski C, Ghio AJ, Higgins D, Porubcin M, Moore EG, Hainsworth LN, Umbreit JN, Conrad ME, Feng L, Lis A, Roth JA, Singleton S, Garrick LM (2003) DMT1: a mammalian transporter for multiple metals. Biometals $16: 41-54$

30. Roth JA, Garrick MD (2003) Iron interactions and other biological reactions mediating the physiological and toxic actions of manganese. Biochem Pharmacol 66:1-13

31. Howitt J, Putz U, Lackovic J, Doan A, Dorstyn L, Cheng H, Yang B, Chan-Ling T, Silke J, Kumar S, Tan SS (2009) Divalent metal transporter 1 (DMT1) regulation by Ndfip1 prevents metal toxicity in human neurons. Proc Natl Acad Sci USA 106: 15489-15494. doi:10.1073/pnas.0904880106

32. Chen P, Chakraborty S, Mukhopadhyay S, Lee E, Paoliello MM, Bowman AB, Aschner M (2015) Manganese homeostasis in the nervous system. J Neurochem 134:601-610. doi:10.1111/jnc. 13170

33. Salazar J, Mena N, Hunot S, Prigent A, Alvarez-Fischer D, Arredondo M, Duyckaerts C, Sazdovitch V, Zhao L, Garrick LM,
Nuñez MT, Garrick MD, Raisman-Vozari R, Hirsch EC (2008) Divalent metal transporter 1 (DMT1) contributes to neurodegeneration in animal models of Parkinson's disease. Proc Natl Acad Sci USA 105:18578-18583. doi:10.1073/pnas.0804373105

34. Zheng W, Xin N, Chi ZH, Zhao BL, Zhang J, Li JY, Wang ZY (2009) Divalent metal transporter 1 is involved in amyloid precursor protein processing and Abeta generation. FASEB J 23:4207-4217. doi:10.1096/fj.09-135749

35. Ji C, Kosman DJ (2015) Molecular mechanisms of non-transferrin-bound and transferring-bound iron uptake in primary hippocampal neurons. J Neurochem 133:668-683. doi:10.1111/jnc. 13040

36. He L, Girijashanker K, Dalton TP, Reed J, Li H, Soleimani M, Nebert DW (2006) ZIP8, member of the solute-carrier-39 (SLC39) metal-transporter family: characterization of transporter properties. Mol Pharmacol 70:171-180

37. Fujishiro H, Yano Y, Takada Y, Tanihara M, Himeno S (2012) Roles of ZIP8, ZIP14, and DMT1 in transport of cadmium and manganese in mouse kidney proximal tubule cells. Metallomics 4:700-708. doi:10.1039/c2mt20024d

38. Schizophrenia Working Group of the Psychiatric Genomics (2014) Consortium biological insights from 108 schizophreniaassociated genetic loci. Nature 511:421-427

39. Tuschl K, Clayton PT, Gospe SM Jr, Gulab S, Ibrahim S, Singhi P, Aulakh R, Ribeiro RT, Barsottini OG, Zaki MS, Del Rosario ML, Dyack S, Price V, Rideout A, Gordon K, Wevers RA, Chong WK, Mills PB (2012) Syndrome of hepatic cirrhosis, dystonia, polycythemia, and hypermanganesemia caused by mutations in SLC30A10, a manganese transporter in man. Am J Hum Genet 90:457-466

40. Quadri M, Federico A, Zhao T, Breedveld GJ, Battisti C, Delnooz C, Severijnen LA, Di Toro Mammarella L, Mignarri A, Monti L, Sanna A, Lu P, Punzo F, Cossu G, Willemsen R, Rasi F, Oostra BA, van de Warrenburg BP, Bonifati V (2012) Mutations in SLC30A10 cause parkinsonism and dystonia with hypermanganesemia, polycythemia, and chronic liver disease. Am J Hum Genet 90:467-477

41. Battaglia G, Cannella M, Riozzi B, Orobello S, Maat-Schieman ML, Aronica E, Busceti CL, Ciarmiello A, Alberti S, Amico E, Sassone J, Sipione S, Bruno V, Frati L, Nicoletti F, Squitieri F (2011) Early defect of transforming growth factor $\beta 1$ formation in Huntington's disease. J Cell Mol Med 15:555-571. doi:10.1111/j. 1582-4934.2010.01011.x

42. Narayanan KL, Chopra V, Rosas HD, Malarick K, Hersch S (2015) Rho kinase pathway alterations in the brain and leukocytes in Huntington's disease. Mol Neurobiol. doi:10.1007/s12035015-9147-9 